\title{
Sobre a relação entre Cultura e Desenvolvimento: alguns apontamentos em defesa do conceito antropológico de cultura
}

\author{
Ivann Carlos Lago
}

Universidade Federal da Fronteira Sul/Campus Cerro Largo

Edemar Rotta

Universidade Federal da Fronteira Sul/Campus Cerro Largo

\section{Resumo}

O texto se insere no rol de contribuições teórico-conceituais ao debate sobre a relação entre cultura e desenvolvimento. Defende a importância da adoção do conceito antropológico (amplo) de cultura como condição para uma compreensão abrangente da complexidade social a ser utilizada no âmbito dos estudos sobre desenvolvimento, desde o diagnóstico às tentativas de promovê-lo. Adicionalmente, subscrevem-se alguns alertas metodológicos, principalmente em função das armadilhas do romantismo e do determinismo no campo das pesquisas sobre cultura e de como ela pode relacionar-se com o desenvolvimento.

Palavras-chave: Cultura. Desenvolvimento. Delimitação Conceitual.

On the relation between Culture and Development: some notes in defense of the anthropological concept of culture

\begin{abstract}
The text is part of the role of theoretical-conceptual contributions to the debate on the relation between culture and development. It defends the importance of adopting the (broad) anthropological concept of culture as a condition for a comprehensive understanding of the social complexity to be used in development studies, from diagnosis to attempts to promote it. In addition, some methodological alerts are subscribed, mainly due to the traps of romanticism and determinism in the field of research on culture and how it can relate to development.
\end{abstract}

Key-words: Culture. Development. Conceptual Delimitation. 
Sobre a relação entre Cultura e Desenvolvimento: alguns apontamentos em defesa do conceito antropológico de cultura

\title{
Sobre la relación entre Cultura y Desarrollo: algunos apuntes en defensa del concepto antropológico de cultura
}

\begin{abstract}
Resumen
El texto se inserta en el rol de contribuciones teórico-conceptuales al debate sobre la relación entre cultura y desarrollo. Defende la importancia de la adopción del concepto antropológico (amplio) de cultura, como condición para una comprensión integral de la complejidad social a ser utilizada en el ámbito de los estudios sobre desarrollo, desde el diagnóstico a los intentos de promoverlo. Adicionalmente, se suscriben algunas alertas metodológicas, principalmente en función de las trampas del romanticismo y del determinismo en el campo de las investigaciones sobre cultura y de cómo puede relacionarse con el desarrollo.
\end{abstract}

Palabras clave: Cultura. Desarrollo. Delimitación Conceptual.

\section{Introdução}

Quando se trata de pesquisa, em especial aquelas no mundo acadêmico, a delimitação dos conceitos que orientarão a investigação está entre as etapas mais importantes. Dela depende todo o restante do trabalho. E quando existem diferentes possibilidades de significação conceitual envolvidas, a delimitação adquire ainda mais centralidade. É o caso dos estudos que tratam da relação entre cultura e desenvolvimento, pois se utilizam de dois conceitos - "cultura" e "desenvolvimento" - que estão entre os mais polissêmicos no mundo das ciências humanas e sociais.

Este artigo tem a intenção de contribuir com o complexo e necessário debate sobre a importância da delimitação conceptual dos termos "cultura" e "desenvolvimento", especialmente no âmbito das pesquisas que tratam da relação entre eles. Defende-se a adoção de perspectivas mais abrangentes em ambos os casos, e apresentam-se alguns argumentos em sua defesa. De modo especial, argumenta-se em favor do significado antropológico do conceito de cultura, o qual remete à sua utilização não apenas como elemento representativo e significador da complexidade social, mas como argamassa constitutiva de todos os outros elementos e potencialmente interveniente em todos os aspectos sociais, políticos e econômicos que envolvem diagnósticos e políticas de desenvolvimento.

Também subscrevem-se alguns alertas metodológicos, principalmente em função das armadilhas do romantismo e do determinismo no campo das pesquisas sobre cultura e de como ela pode relacionar-se com o desenvolvimento.

\section{Sobre a delimitação conceptual no debate da relação entre cultura e desenvolvimento.}

Reflexões que se debrucem sobre o tema da "cultura", seja como objeto de análise em si ou na relação com outros temas, precisam começar por definir em que sentido se irá tomar o conceito. Os textos que tratam da relação entre cultura e desenvolvimento, via de regra, adotam uma entre as duas já clássicas definições do termo: "cultura" em sentido amplo ou antropológico e "cultura" em sentido 
restrito ou de produção cultural. Não se entrará, aqui, no debate sobre as origens, os fundamentos, os significados e as implicações de cada uma das abordagens, por se considerar que a literatura sobre o assunto já é bastante rica de esforços para sua delimitação e diferenciação'. Os trabalhos de Harrison e Huntington (2002), Rist (2002), Hermet (2002), Loiola e Miguez (2007), Trennepohl et al. (2007) e Dallabrida (2007) são alguns bons exemplos neste campo.

Para efeito das reflexões aqui apresentadas, adota-se a compreensão de cultura sempre em sentido amplo ou antropológico. Tal abordagem também comporta diversas definições, e cada autor costuma apresentar a sua. Mas, embora com algumas variações, todas elas tendem a concordar quanto ao nível de abrangência e complexidade do conceito. Nesse sentido, a proposição de Botelho (2001) nos parece bastante clara. Segundo essa autora,

na dimensão antropológica, a cultura se produz através da interação social dos indivíduos, que elaboram seus modos de pensar e sentir, constroem seus valores, manejam suas identidades e diferenças e estabelecem suas rotinas. Desta forma, cada indivíduo ergue à sua volta, e em função de determinações de tipo diverso, pequenos mundos de sentido que lhe permitem uma relativa estabilidade. (...) Os fatores que presidem a construção desse universo protegido podem ser determinados pelas origens regionais de cada um, em função de interesses profissionais ou econômicos, esportivos ou culturais, de sexo, de origens étnicas, de geração, etc. Na construção desses pequenos mundos, em que a interação entre os indivíduos é um dado fundamental, a sociabilidade é um dado básico. (BOTELHO, 2001, p.76).

Note-se que, no seu sentido ampliado ou "antropológico", a cultura envolve todas as dimensões, tanto em termos simbólicos quanto materiais, de produção, reprodução, significação, interpretação e vivência do mundo humano. Diz respeito, portanto, ao modo como o ser humano vê a si mesmo e ao mundo, como se vê diante do próprio mundo e como parte dele, como se apropria do cotidiano e como se relaciona com ele (LOIOLA e MIGUEZ, 2007).

Mas a questão do significado não é algo que diz respeito apenas ao conceito de cultura. A polissemia também é um atributo do conceito de desenvolvimento, quer em suas abordagens históricas, teóricas, metodológicas ou de aplicabilidade prática na análise das sociedades (FURTADO, 2000; POCHMANN, 2004; SACHS, 2004; VEIGA, 2005; ROTTA, 2007; FONSECA, 2014; RANDOLPH, 2016; entre outros), a tal ponto de Siedenberg (2006, p. 01) referir que

durante as últimas cinco décadas o tema do desenvolvimento ocupou um lugar de destaque nas ciências sociais e econômicas, na discussão política, na mídia e nas políticas públicas. Apesar disso nunca houve unanimidade em torno desse conceito e, principalmente, como o desenvolvimento pode ou deve ser fomentado.

\footnotetext{
${ }^{1}$ Para uma definição conceitual dos dois significados, ver: RIST, Gilbert. La cultura y el capital social. Cómplices o víctimas del desarrollo? In: KLIKSBERG, Bernardo; TOASSINI, Luciano (Orgs.). Capital social y cultura: claves estratégicas para el desarrollo. Buenos Aires, 2000. p. 129-150.
} 
Este artigo não intenta entrar na seara de debates sobre o conceito de desenvolvimento, até mesmo por considerar que a literatura ${ }^{2}$ das áreas de ciências humanas, sociais e sociais aplicadas já faz isso com profusão e as contribuiçõos estabelecidas são as referências para este estudo.

Nos estudos sobre desenvolvimento, a dimensão da cultura ganha espaço a partir dos questionamentos levantados à economia clássica pelos economistas neoclássicos, pelos defensores do liberalismo social, pelos anarquistas, pelos socialistas (utópicos e científicos), por Schumpeter e Keynes, entre outros. Porém, o impulso decisivo para sua inserção definitiva nos debates, em muitos casos como aspecto essencial na dinâmica de desenvolvimento das sociedades, decorre das teorias do desenvolvimento produzidas no pós $2^{\text {a }}$ Guerra Mundial, com destaque para as teorias da modernização, da dependência e dos polos de crescimento, que tiveram grande influência na construção das propostas implantadas no Brasil, bem como seus principais questionamentos (ROTTA, 2007).

No cenário mais recente, especialmente decorrente da crise do capitalismo e do socialismo real, no último quarto do século $X X$, emergem novas teorias, tais como: do capital humano, do capital social, do desenvolvimento endógeno, dos meios inovadores, dos distritos tecnológicos, dos tecnopolos, do empowerment, do novo desenvolvimentismo, do socialismo do século XXI, da globalização, da sustentabilidade, do city marketing, das redes de cidades e regiões, da ordem internacional sem fronteiras, entre outras (KLINK, 2001; BECKER e WITTMANN, 2003; VEIGA, 2005; ROTTA, 2007; RIFFO, 2013).

Estas teorias mais recentes, para além de suas abordagens divergentes, deixam evidente que o desenvolvimento é um fenômeno localizado, multidimensional e complexo que implica um processo de transformação da estrutura produtiva, das relações sociais, das instituições, da organização política, das bases culturais e da própria relação dos seres humanos com a natureza. É um fenômeno que acontece na dinâmica das relações sociais, produto das relações tensas e contraditórias que se estabelecem no interior das formações sociais e na relação destas com as demais, em cenários multiescalares e, como tal, é objeto do jogo de forças, dos conflitos de classe, dos interesses dos diferentes grupos, das políticas públicas, dos governos e dos organismos nacionais e internacionais (ROTTA et al, 2016).

Esta compreensão de desenvolvimento apresenta uma perspectiva abrangente, capaz de dar conta do conjunto de variáveis necessárias para assegurar às pessoas as condições para viverem de forma plena, digna, com qualidade e com liberdade. Ela possui afinidade com a definição já apresentada em 1982, na Conferência Mundial sobre Políticas Culturais, realizada pela UNESCO, no México:

o desenvolvimento só tem um verdadeiro sentido quando permite aos indivíduos e aos povos viver melhor e realizar na plenitude suas aspirações morais, espirituais e o pleno florescimento de suas faculdades criadoras. (UNESCO, 1982, p. 18).

\footnotetext{
${ }^{2}$ Amplo espectro desta literatura pode ser visualizado em Sachs (2000), Veiga (2005), Siedenberg (2006), entre outros.
} 
Advoga-se o potencial dessa perspectiva não apenas por que ela é abrangente o suficiente para dar conta da complexidade de fatores que precisam ser tomados em conta ao tratar do desenvolvimento, mas também por que ela já traz, em si, aspectos epistemológicos que facilitam sua "conexão" com o debate sobre a cultura, objeto das reflexões que são apresentadas a seguir.

Outro cuidado importante e necessário nesse debate é com as tentações do maniqueísmo no que tange à relação entre cultura e desenvolvimento. De um lado, um considerável número de estudos, conforme apontado por Harrison (2015) tem se agarrado ao romantismo das abordagens culturalistas, afirmando que, por ter valor em si, toda cultura precisa ser valorada pelo que é; que não existem culturas mais ou menos propensas ao desenvolvimento, e que qualquer empreitada que o busque deve fazê-lo assegurando-se de que não implicará em qualquer interferência sobre características culturais. De outro, temos todo um conjunto de abordagens deterministas segundo as quais existem culturas como que predestinadas ao desenvolvimento, ao passo que outras seriam tóxicas a ele (HARRISON e HUNTINGTON, 2002). Novamente, a intenção aqui não é explorar à exaustão argumentos, pressupostos e implicações das duas perspectivas, mas chamar a atenção para suas limitações. Seja por desconsiderar totalmente o potencial da cultura para o desenvolvimento, seja pelo reducionismo determinista de conceber culturas "pró" e "anti" desenvolvimento, essas posturas pouco contribuem para o debate e, frequentemente, levam a compreensões bastante limitadas, tanto da cultura quanto do próprio desenvolvimento.

Pelos motivos expostos acima, parece profícuo o modelo epistemológico e de análise que remonta a Max Weber, especialmente em seus estudos sobre a relação entre A Ética Protestante e o Espírito do Capitalismo (WEBER, 2004). A referência, aqui, se dá especificamente ao pressuposto estruturante segundo o qual não é a cultura em si que deve ser tomada como mais ou menos propensa ao desenvolvimento, mas o conjunto de crenças, valores, tradições, símbolos que, separadamente ou em conjunto, orientam e definem comportamentos e atitudes, estes, sim, mais ou menos favoráveis a produzir determinados padrões societários necessários ao desenvolvimento. Trata-se, portanto, de compreender a cultura para, no seu interior, identificar os elementos definidores de certos padrões comportamentais cujos efeitos constituem condição necessária, ou não, ao desenvolvimento. Nesse sentido é que poderemos afirmar que uma certa cultura é mais ou menos propensa ao desenvolvimento se, e na medida em que, valoriza e induz a determinados comportamentos socioeconômicos, éticos e políticos que, quando generalizados, produzem os efeitos considerados desejáveis a partir de certos padrões conceituais que definem o desenvolvimento.

Por isso, não se trata apenas de pensar sobre como a cultura pode ser um fator de desenvolvimento, ou mesmo um entrave a ele, mas de refletir sobre como ela constitui o substrato socioeconômico, ético e político a partir do qual determinado modelo de desenvolvimento pode se dar. Essa lição já foi ensinada por Weber (2004). Ele nunca disse que a cultura americana era mais propensa ao desenvolvimento econômico. O que ele fez foi identificar, na estrutura das religiões protestantes, os elementos específicos em torno dos quais se organizam comportamentos também específicos, esses, sim, positivamente associados a padrões de ação coletiva que são a base do desenvolvimento econômico. É a ética 
protestante, especialmente em sua concepção sobre o trabalho, a disciplina, o dinheiro e a poupança, que potencializa o desenvolvimento econômico. E essa ética é uma das dimensões que compõem a cultura protestante que, por sua vez, constitui, juntamente com outros elementos simbólicos e identitários, a cultura norte-americana - ou estadunidense, para ser mais preciso conceitualmente, e para assegurar que não se está generalizando a análise para grupos culturais que não são representativos dessa cultura (como os do México e Canadá, e mesmo subgrupos dentro dos Estados Unidos).

A questão, portanto, é compreender, em cada cultura, os fatores específicos que podem potencializar ou dificultar o desenvolvimento a partir da influência que exercem sobre as crenças, atitudes e comportamentos cotidianos das pessoas. É nesse sentido que se pode afirmar: sim, a cultura importa! E é nesse mesmo sentido que a cultura precisa ser tomada nas análises sobre o sucesso ou fracasso de políticas públicas e de programas de desenvolvimento. Afinal, não se trata de identificar, na cultura, a chave para explicar por que essa ou aquela iniciativa fracassou ou foi bem sucedida, mas de compreender a fundo o contexto cultural para identificar, no seu bojo, elementos constitutivos dos padrões coletivos de opinião e comportamento que, em suas manifestações empíricas, contribuem ou não para a consecução dos objetivos que se pretendia com a política em análise.

$\mathrm{E}$ isso, obviamente, também vale para a fase do diagnóstico e do planejamento. É preciso ir fundo nos elementos constitutivos da cultura, a fim de identificar padrões de crenças, valores e atitudes coletivos, como condição básica para inferir sobre as potencialidades de determinada ação, e sobre as alternativas de ajustes a serem feitos para maximizar seus resultados.

\section{Uma defesa do "conceito antropológico" de cultura nos estudos sobre desenvolvimento}

Assumiu-se, acima, o argumento segundo o qual qualquer debate sobre a relação entre cultura e desenvolvimento precisa, como condição para que seja teoricamente produtivo, explicitar minimamente as noções de cultura e de desenvolvimento sobre as quais se estrutura. O simples fato de assumir, por exemplo, a noção antropológica - portanto, mais ampla - de cultura, implica em assumir que grande parte do que se diz sobre desenvolvimento precisa não apenas considerar a dimensão cultural, mas, inclusive, ser redefinido em função dela. Ou, dito de outro modo, a própria concepção do que seja desenvolvimento precisa ser compreendida culturalmente.

O “problema", no sentido teórico e metodológico do termo, é que a globalização econômica fez florescer todo um arcabouço de crítica e resistência ao processo de mundialização da cultura. Com isso, a cultura, em seu sentido antropológico, ainda continua distante do planejamento governamental em âmbito internacional e mesmo nacional. Tal debate se limita, em geral, a iniciativas de âmbito local e regional, centradas na concepção restrita de cultura e geralmente voltadas à promoção de identidades culturais regionais, frequentemente concebidas como "potencialidades" para o desenvolvimento econômico. Esse é o motivo pelo qual, embora estudos sobre desenvolvimento tenham contado com a participação de cientistas sociais (especialmente antropólogos) desde os anos 1960, 
ainda hoje a cultura raramente é tomada como elemento central nesses estudos (HARRISON, 2015). Exceções, é claro, existem. No caso do Brasil, as reflexões de Celso Furtado, Florestan Fernandes, Renato Ortiz, Roberto DaMatta são exemplos que, embora não sejam foco deste texto, merecem referência como esforços importantes em torno de uma compreensão mais abrangente da cultura e de suas múltiplas formas de se relacionar com o tema do desenvolvimento.

Por outro lado, sob vários aspectos, pode-se dizer que a abordagem "romântica" da cultura tem sido predominante nos estudos da área, fortalecendo a tese de que tudo o que é definido como "cultural" é bom em si mesmo, e que precisa ser mantido e respeitado como elemento identitário de grupos e regiões (HARRISON, 2015). Isso implica assumir que, no que diz respeito à cultura, nada pode nem deve ser alterado, nenhuma interferência pode ser feita, a não ser para transformar elementos da cultura em mercadoria vendável e, com isso, elevar marcas culturais à categoria de fatores de desenvolvimento econômico. Turismo, gastronomia, folclore, festividades, são exemplos de elementos culturais que são tomados em conta não como objeto de análise, mas como características com potencial para gerar desenvolvimento, especialmente aquele de dimensões regionais, ao serem transformados em produto comercial.

Esse é um dos motivos, por exemplo, de serem tão escassos e superficiais os diagnósticos a partir dos quais planos de desenvolvimento (especialmente territorial) são concebidos e implantados. Não falta apenas a incorporação da cultura como elemento estruturante das políticas; falta, inclusive, uma compreensão mínima do que seja cultura, de como ela atua e de como pode ser incorporada ao planejamento governamental. Falta, enfim, a incorporação da cultura como elemento central dos diagnósticos que precisam subsidiar políticas públicas nas diversas áreas, inclusive do desenvolvimento. A cultura quase nunca é investigada como estrutura a partir da qual os planos de desenvolvimento serão materializados. Ela geralmente é tomada como insumo, como fator direto de desenvolvimento, e não como variável a ser problematizada e compreendida em toda a sua complexidade.

Um exemplo para ilustrar esta questão é todo o volume de discussões ${ }^{3}$ e iniciativas ${ }^{4}$ que buscam promover o desenvolvimento dos pequenos municípios na Região das Missões, no noroeste do Estado do Rio Grande do Sul, no Sul do Brasil. $\mathrm{Na}$ sua grande maioria, esses esforços se limitam a identificar e descrever as características que definem essa região, em especial o seu "caráter rural" e a sua "identidade missioneira”, para então indicar quais políticas devem ser adotadas para valorar essas características e transformá-las em fatores de desenvolvimento. Assume-se, como pressuposto, que essas duas dimensões (ruralidade e missioneirismo) são definidoras da região, que são a essência de sua identidade e que, por isso, devem ser os grandes propulsores de seu desenvolvimento. Assim, do mapeamento e descrição desses dois "elementos culturais", parte-se diretamente

\footnotetext{
3 Exemplos disso podem ser visualizados em Rio Grande do Sul (2006 e 2015).

4 Manifestas, de forma permanente, em movimentos, instituições e organizações sociais que procuram apontar perspectivas de desenvolvimento, especialmente, por meio da exploração do turismo, tendo em vista que a região possui um conjunto de cinco remanescentes dos povoados implantados no processo de evangelização promovido pelos jesuítas durante os séculos XVII e XVIII, inscritos na lista de Patrimônio Mundial da Humanidade.
} 
para a indicação de políticas que, através de sua valorização e divulgação, induziriam ao desenvolvimento.

Mas isso é suficiente como diagnóstico? Ou outras perguntas também deveriam ser respondidas? Quais elementos deveriam compor, por exemplo, um diagnóstico amplo e profundo sobre a condição de ruralidade dessa região e sobre como ela influencia crenças e comportamentos? Se o caráter rural for, de fato, tomado como um valor a ser "preservado", como conceber estratégias e modelos de desenvolvimento sem que o ímpeto da urbanização lhe seja uma ameaça? Quais seriam, em termos sociológicos, os elementos dessa ruralidade que deveriam ser preservados e potencializados no âmbito de um modelo de desenvolvimento endógeno de caráter "humano", "sustentável" e "libertário"? Em que medida as "visões" sobre o rural e a ruralidade poderiam interferir, para ou bem ou para o mal, em planos de desenvolvimento local? Qual o estoque de "capital humano" e de "capital social" que essa região possui - ou não - para potencializar o desenvolvimento? Quais as influências que o catolicismo, como religião predominante, exerce sobre as crenças, hábitos e comportamentos socioeconômicos dos indivíduos e grupos sociais que vivem nessa região?

Essas são perguntas fundamentais, e sem suas respostas qualquer plano de desenvolvimento regional será, por definição, frágil e incompleto. E as pesquisas necessárias para responder a essas perguntas precisam evitar as tentações do maniqueísmo do qual se falou anteriormente. Tanto o romantismo culturalista quanto o determinismo da cultura, se assumidos de antemão à pesquisa, reduzem ao proselitismo acadêmico investigações que teriam potencial para produzir resultados de grande valor científico. A questão, portanto, é epistemológica muito antes de ser social, econômica, política ou de gestão.

É preciso conhecer a fundo os elementos que caracterizam a cultura em questão, para então definir quais aspectos são mais ou menos propensos a fomentar comportamentos e atitudes positivamente associadas ao desenvolvimento que essa mesma sociedade busca em um dado momento e espaço. E é necessário, ainda, honestidade intelectual para apontar quais desses aspectos precisam ser potencializados, modificados ou mesmo desenvolvidos por estarem completamente ausentes. Convencer as pessoas a investir em poupança e planos de previdência privados será um grande desafio em uma cultura na qual a crença predominante é de que o futuro está inteiramente nas mãos de Deus. E vejam que dizemos "difícil", não "impossível”; é o profundo conhecimento da complexidade dos elementos culturais que permitirá identificar as estratégias que poderão ter sucesso em uma empreitada dessa natureza.

\footnotetext{
Em síntese, o desenvolvimento passa a ser assumido como um fenômeno endógeno, em busca de relações de preservação com o ambiente, aberto ao câmbio institucional e dependente da história, que se realiza sobre territórios, e que, por isso tudo, é dependente de fatores externos e internos a esses territórios (LOIOLA e MIGUEZ, 2007, p. 4).
}

Considerar a cultura, portanto, não pode significar a negligência de questões históricas, tradicionais, religiosas, educacionais, políticas, ideológicas, econômicas, institucionais, normativas e até mesmo de conjuntura. Por exemplo, uma potencial ameaça ao desenvolvimento endógeno de âmbito local é a tendência de se 
negligenciar as tensões ideológicas, os conflitos políticos e as relações de poder que atuam no âmbito do território - tanto quanto no âmbito nacional ou internacional. o "local" é tão marcado pelos conflitos de interesse e pelas disputas políticas quanto o "nacional", e a caracterização de uma dada região a partir de elementos culturais não pode se render à tentação da homogeneização. Determinados traços culturais podem ser característicos e definidores de uma região, mas isso não significa que sejam unânimes, nem que não tenham sua predominância associada a violências simbólicas e conflitos internos a partir dos quais outras características do mesmo grupo tenham sido sobrepujadas. E qualquer política pública que se volte à valorização e promoção dessa "identidade cultural" tem potencial para despertar e trazer à tona as disputas internas que definiram como derrotados os outros elementos constitutivos de subculturas dentro desse mesmo grupo.

Por isso - e é importante insistir nessa questão - há que se ter todo o cuidado possível com os romantismos em relação à cultura e seus elementos constitutivos. A cultura de uma nação, de um grupo ou de um território, é um constructo histórico, em grande medida resultado e expressão de conflitos passados internos ao grupo em questão, e que manifesta, em boa medida, as visões de mundo e os valores dos grupos que, politicamente, foram predominantes. Em outras palavras, a cultura de uma dada sociedade é, sob vários aspectos, a cultura dos subgrupos dominantes naquela sociedade. Por isso, qualquer ação que busque a transformação dos padrões de organização social, econômica e política de um dado grupo humano, encontrará a resistência dos subgrupos a quem o atual padrão societário proporciona poder e privilégios. E toda vez que nos esquecemos disso em nossos diagnósticos e programas de desenvolvimento, diminuímos consideravelmente suas chances de sucesso.

Porém, compreender, encarar e assumir a dimensão do conflito, das contradições, da dominação e das resistências, não implica afirmar que estas não possam ser mediadas na dimensão da construção de projetos e propostas de desenvolvimento que estabeleçam objetivos comuns, minimamente acordados ou concertados (CORDOVA, 1985), que possam trazer melhoria das condições de vida da população de um território específico. Minimizar ou desprezar os conflitos e contradições, isto sim, pode limitar a inclusão e a participação efetiva dos diferentes sujeitos.

Aqui fica evidente o motivo pelo qual se defende a perspectiva antropológica (ampla) como a mais frutífera para os estudos que tratam da relação entre cultura e desenvolvimento. O verdadeiro impacto da cultura sobre o desenvolvimento será compreendido se a tomarmos como aquele substrato que organiza e orienta os modos de pensar, de agir e de viver das pessoas. A questão vai muito além de "vender" elementos culturais para gerar desenvolvimento. É preciso compreender e assumir que nada existe fora da cultura, que ela é a fonte das crenças e valores em função dos quais as pessoas organizam o que fazem e definem quem são.

[...] do ponto de vista de sua concepção mais ampliada, a dimensão cultural é estratégica para o desenvolvimento pelo fato de que a cultura é a argamassa dos pactos celebrados entre os vários atores sociais e as políticas e projetos de desenvolvimento devem traduzir concertações dessa natureza (...). Daí, por conseguinte, é fundamental que a dimensão cultural marque presença em todos os centros de decisão governamental 
e, assim, corte de maneira transversal o conjunto das políticas públicas que se ocupam do desenvolvimento [...]. (LOIOLA e MIGUEZ, 2007, p. 11).

Isso não significa que a transformação de elementos culturais específicos em "mercadorias" e, como tais, em fatores de desenvolvimento econômico, especialmente através da geração de renda, não seja uma possibilidade a se considerar em planos de desenvolvimento. Pelo contrário. A geração e distribuição de renda por meio da "exploração" de elementos culturais pode ser uma importante ferramenta para o desenvolvimento econômico, especialmente se este estiver no centro dos objetivos que são buscados através de planos maiores, dentro dos quais ela ocupa lugar de destaque.

A questão é que essa não pode ser a única, nem mesmo a mais importante, ação a ser adotada. Não se trata de negar, categoricamente, a economia da cultura, mas de pensar o tema como uma via de mão dupla, na qual a culturalização da economia - assim como da política, da ética, da gestão - adquire a mesma importância e magnitude. Afinal, o próprio desenvolvimento do capitalismo, por exemplo, baseado na sociedade do consumo, precisa, como condição para se desenvolver, de uma disseminação global da cultura do consumo que the sirva de base e lhe dê sustentação.

O ponto fundamental é que:

[...] o potencial de geração de riqueza e de empregos representado pela cultura não pode ser separado de uma visão ampliada da cultura, como geradora de riquezas simbólicas. Não se trata, portanto, apenas de perseguir o crescimento econômico por meio do estímulo às atividades ligadas à cultura, mas, também, e principalmente, de criar as condições propícias ao aumento da diversidade das manifestações culturais, promovendo a inclusão, simultaneamente cultural, social e econômica, de novos e múltiplos agentes criadores. (LOIOLA e MIGUEZ, 2007, p. 13).

Todos esses elementos reforçam a importância, a necessidade e mesmo a urgência da incorporação de perspectivas conceitualmente mais abrangentes nos estudos sobre a relação entre cultura e desenvolvimento. A cultura não é apenas uma variável a ser considerada quando se pensa o desenvolvimento. Ela é parte integrante, constitutiva e estruturante de todos os outros elementos. E políticas públicas voltadas ao desenvolvimento não precisam apenas ser concebidas considerando fatores culturais em sua configuração. Elas precisam dialogar diretamente com a cultura em seu sentido amplo, seja em termos de escolha das melhores ações e estratégias, seja no que se refere aos impactos de médio e longo prazo e também das possibilidades de alteração dos próprios padrões culturais.

\section{Considerações finais}

O desafio de incorporar a cultura como fator estruturante de todo modelo de organização social e, por decorrência, de todo modelo de desenvolvimento, é tão urgente quanto complexo. Sua complexidade se apresenta maior sempre que estudos acadêmicos se propõem a analisar a fundo a relação entre 0 desenvolvimento e a cultura. Tais análises são urgentes, fundamentais e 
determinantes para as necessárias mudanças, seja nos estudos sobre o desenvolvimento, seja nas tentativas de promovê-lo.

Felizmente, parece haver uma maior disposição, tanto no mundo acadêmico quanto político e até mesmo dos negócios, para reconhecer à cultura o lugar que Ihe cabe nas reflexões sobre o desenvolvimento. Importantes agentes políticos mundiais, como o ex-presidente do Banco Central dos Estados Unidos, Alan Greespan, têm se rendido à importância da cultura. Nas palavras dele: "Eu costumava pensar que o capitalismo era a natureza humana. Mas não é. O capitalismo é cultura". No mundo acadêmico, ocorre o mesmo. David Landes, um dos maiores expoentes da história econômica no Século XX, afirmou categoricamente que "Max Weber estava certo. Se aprendemos algo a partir da história do desenvolvimento econômico, foi que a cultura faz toda a diferença" (LANDES, 1998).

A cultura importa! Parece que caminhamos cada vez mais para o consenso em torno dessa afirmação. Contudo, ainda é longo o caminho a ser percorrido no que se refere à delimitação do que seja cultura, e em qual sentido ela deve ser tomada nos estudos sobre o desenvolvimento. Nessa jornada, sutilezas epistemológicas e armadilhas conceituais nos esperam a cada curva do caminho. Conhecê-las e munir-se de arcabouços analíticos mais eficazes no enfrentamento da complexidade do tema não são garantias de análises mais profundas, mas asseguram um bom começo.

A adoção do significado antropológico - mais amplo e complexo - de cultura, a retomada dos preceitos weberianos de análise da cultura e de sua relação com as outras dimensões da vida social, a (re)significação do conceito de desenvolvimento, são preceitos potencialmente produtivos e de grande valia, tanto para os estudos sobre desenvolvimento quanto na concepção e implantação de programas para promovê-lo. A cultura como fator de desenvolvimento é um campo de estudos que poderá crescer muito e rapidamente nas próximas décadas. $\mathrm{E}$ a solidez de seus resultados e descobertas dependerá diretamente da capacidade dos pesquisadores de compreender a cultura em toda a sua complexidade, e de assumila como uma categoria que, para além de ser importante em si mesma, é constitutiva e determinante de todas as outras categorias e variáveis que se possa considerar.

Por isso, não basta pensar a cultura como um fator de desenvolvimento, nem em possibilidades de desenvolvimento a partir de elementos culturais, embora isso seja importante. A cultura precisa ser categoria transversal, presente em todas as iniciativas de pensar e promover o desenvolvimento, variável e preocupação presente em todas as instâncias e instituições, acadêmicas e governamentais, que têm o desenvolvimento como objeto de análise ou como meta de ação. $E$ tudo isso sem sucumbir às tentações, tanto do romantismo quanto do determinismo da cultura.

\section{REFERÊNCIAS}

BECKER, Dinizar F.; WITTMANN, Milton L. (Orgs.). Desenvolvimento regional: abordagens interdisciplinares. Santa Cruz do Sul: Edunisc, 2003. 
Sobre a relação entre Cultura e Desenvolvimento: alguns apontamentos em defesa do conceito antropológico de cultura

BOTELHO, Isaura. Dimensões da cultura e políticas públicas. São Paulo em Perspectiva, São Paulo, v.15, n. 2, p. 73-83, abr./jun. 2001.

CÓRDOVA, Efrén. PACTOS SOCIAIS: Experiência internacional, tipologia e modelos. Brasília: Ministério do Trabalho; São Paulo: IBRART - Instituto Brasileiro de Relações de Trabalho, 1985.

DALLABRIDA, Valdir. R. Economia, cultura e desenvolvimento: uma aproximação sobre as origens teóricas da abordagem do tema. Revista Brasileira de Gestão e Desenvolvimento Regional. v. 7, n. 2, p. 282-299, mai/ag. 2011.

FONSECA, Pedro D. C. Desenvolvimentismo: a construção do conceito. In: CALIXTRE, André B.; BIANCARELLI, André M.; CINTRA, Marcos A M. (Orgs.). Presente e futuro do desenvolvimento brasileiro. Brasília: IPEA, 2014, p. 31-78.

FURTADO, Celso. Introdução ao desenvolvimento: enfoque histórico-estrutural. 3.ed. revista pelo autor. Rio de Janeiro: Paz e Terra, 2000.

HARRISON, Lawrence E.; HUNTINGTON, Samuel P. (Orgs.). A Cultura Importa: os valores que definem o progresso humano. Rio de Janeiro: Record, 2002.

HARRISON, Lawrence E. Cultura e Desenvolvimento Econômico. Disponível em: <http://ordemlivre.org/posts/cultura-e-desenvolvimento-economico--5>. Postado em 04 março 2015. Acesso em: 20 out. 2016.

HERMET, Guy. Cultura \& desenvolvimento. Petrópolis: Vozes, 2002.

KLINK, Jeroen J. A cidade-região: regionalismo e reestruturação no grande $A B C$ paulista. Rio de Janeiro: DP\&A, 2001.

LANDES, David S. A riqueza e a pobreza das nações. São Paulo: Elsevier, 1998.

LOIOLA, Elizabete; MIGUEZ, Paulo. Sobre cultura e desenvolvimento. Anais do Terceiro Encontro de Estudos Multidisciplinares em Cultura. UFBa: Salvador, 23 a 25 de maio de 2007.

ORTIZ, Renato. Cultura e Desenvolvimento. Políticas Culturais em Revista, Salvador, 1(1), p. 122-128, 2008. Disponível em:

<https://portalseer.ufba.br/index.php/pculturais/article/view/3194/2304>. Acesso em: 20 out. 2016.

POCHMANN, Márcio (Org.). Reestruturação produtiva: perspectivas de desenvolvimento local com inclusão social. Petrópolis: Vozes, 2004.

RANDOLPH, Rainer. A tríade de desenvolvimento, planejamento e política (poder): proposições para investigações de transformações e políticas regionais. In: ETGES, 
Virgínia E.; CADONÁ, Marco A. (Orgs.). Globalização em tempos de regionalização: repercussões no território. Santa Cruz do Sul: EDUNISC, 2016, p. 39-62.

REIS, Ana. C. F. Economia da cultura e desenvolvimento sustentável: o caleidoscópio da cultura. Barueri: Manole, 2007.

RIFFO, Luis P. 50 años del ILPES: evolución de los marcos conceptuales sobre desarrollo territorial. Santiago do Chile: CEPAL - Serie Desarrollo Territorial, $n^{\circ} 15$, 2013.

RIO GRANDE DO SUL. Perfis - Regiões Funcionais de Planejamento. Porto Alegre: SEPLAN-RS/DEPLAN, 2015.

RIO GRANDE DO SUL. Rumos 2015 - Estudo de desenvolvimento regional e logística de Transportes no Rio Grande do Sul/SCP-DEPLAN; DCAPET. Porto Alegre: SCP, 2006, 5 v.

RIST, Gilbert. La cultura y el capital social: Cómplices o víctimas del desarrollo? In: KLIKSBERG, Bernardo; TOASSINI, Luciano (Orgs.). Capital social y cultura: claves estratégicas para el desarrollo. Buenos Aires, 2000. p. 129-150.

ROTTA, Edemar. Desenvolvimento regional e políticas sociais no noroeste do estado do Rio Grande do Sul. Porto Alegre, FSS/PUCRS, Tese de Doutorado, 2007.

ROTTA, Edemar et. al. Políticas sociais e desenvolvimento: estudo comparativo do Noroeste do RS nas décadas de 1990 e 2000. Anais do XV ENPESS - Encontro Nacional de pesquisadoras(es) em Serviço Social - Formação e Trabalho Profissional: reafirmando as Diretrizes Curriculares da ABEPSS. Ribeirão Preto/SP. 04 a 09 de 2016. p. 1-14.

SACHS, Ignacy. Desenvolvimento: includente, sustentável, sustentado. Rio de Janeiro: Garamond, 2004.

SACHS, Wolfgang. Dicionário do desenvolvimento: guia para o conhecimento como poder. Petrópolis: Vozes, 2000.

SIEDENBERG, Dieter R. (Coord.). Dicionário do Desenvolvimento Regional. Santa Cruz do Sul: EDUNISC, 2006.

SIEDENBERG, Dieter R. Desenvolvimento: ambiguidades de um conceito. Cadernos EBAPE.BR, v. 04, n. 04, Dez. 2006. Disponível em: < http://bibliotecadigital.fgv.br/ojs/index.php/cadernosebape/article/view/5000/3734>. Acesso em: 29 nov. 2016.

TRENNEPOHL, Dilson. et. al. Desenvolvimento e Cultura: relações de sinergia e conflito. Revista Desenvolvimento em Questão, ljuí, n. 09, p. 147-161, jan/jun.2007. 
UNESCO (Organização das Nações Unidas para Educação, Ciência e Cultura). Declaración de México sobre las políticas culturales. 1982. Disponível em: <http://portal.unesco.org/culture/es/files/12762/112762/1329542/4031mexico_sp.pdf/ me xico_sp.pdf.>. Acesso em: 20 out. 2016.

VEIGA, José E. da. Desenvolvimento sustentável: o desafio do século XXI. Rio de Janeiro: Garamond, 2005.

WEBER, Max. A ética protestante e o espírito do capitalismo. Tradução de José Marcos Mariani de Macedo. São Paulo: Companhia das Letras, 2004.

Ivann Carlos Lago. Mestre em Sociologia Política (UFSC), Doutor em Sociologia Política (UFSC), Professor do quadro permanente do Programa de Mestrado em Desenvolvimento e Políticas Públicas da Universidade Federal da Fronteira Sul, Campus Cerro Largo. Pesquisador em Ideias, Instituições e Práticas Políticas; Partidos e Eleições; Conexão Eleitoral; Teoria Política; Cultura e Desenvolvimento.ivann@uffs.edu.br

Edemar Rotta. Mestre em Sociologia (UFGRS), Doutor em Serviço Social (PUCRS), Pós-Doutorado em Serviço Social (PUCRS). Professor do quadro permanente do Programa de Mestrado em Desenvolvimento e Políticas Públicas da Universidade Federal da Fronteira Sul, Campus Cerro Largo. Pesquisador em Políticas Públicas, Políticas Sociais, Desenvolvimento Regional, Gestão Social, Noroeste do Rio Grande do Sul.erotta@uffs.edu.br 